\title{
Técnicas normativas. Modelos de análisis lingüístico y lógico de enunciados jurídicos aplicables durante su elaboración (estudios de caso)
}

investigacion@pontificia.edu.mx

Marinette Bricard González *

Oscar Gutiérrez Parada

Universidad Pontificia de México, 2006.

Para que el Derecho sea acatado requiere ser interpretado correctamente. De lo contrario, un enunciado jurídico elaborado deficientemente, en especial por el uso y abuso de términos ambiguos y vagos, construcciones sintácticas defectuosas, así como por la falta de sistematización durante el diseño de la estructura interna y externa de una ley, conlleva una afectación del sistema social, en el que su aspecto normativo se ve impactado negativamente, sobre todo en el ámbito de la seguridad jurídica, lo que muestra carencias en el quehacer legislativo.

Con frecuencia los textos del orden jurídico mexicano son inconsistentes, contradictorios, presentan lagunas, así como una inadecuada redacción. Por regla general, estos errores emanan de descuidos o ignorancia; sin embargo, es también factible que las incongruencias e indeterminaciones sean deliberadas.

Uno de los problemas, nada menor, del sistema jurídico radica en las antinomias, que, aunque de manera aislada pueden usarse como enunciados, analizados de manera sistémica representan contradicciones que afectan la seguridad jurídica, tanto del gobernante como de los gobernados. Las contradicciones normativas trastocan el Estado de Derecho debido a que representan un obstáculo para que los operadores lo apliquen. De alguna manera, los actos de aplicación implican actividades interpretativas y éstas conllevan analizar enunciados que entre más claros y precisos permiten su adecuada operación.

Resulta indudable la importancia para el legislador de un adiestramiento en el uso de técnicas normativas con la consecuente capacidad de formular y producir discursos de calidad que impacten positivamente a la sociedad, en términos de efectividad, eficacia y eficiencia. En efecto, una máxima del Derecho instruye que "las mejores leyes son las que dejan poco al arbitrio del juzgador".

Consciente de la carencia cognoscitiva por parte del draftsman en materia de elaboración de textos normativos, Oscar Gutiérrez, especialista ampliamente reconocido, expone varias metodologías cuya finalidad reside en el adiestramiento de la creación legislativa correcta y, por ende, construye (realmente re-construye) modelos con una sólida base científica.

La obra tiene como objetivo la enseñanza de técnicas, las cuales comprenden el estudio de los procesos, actividades y lenguaje óptimos, tanto para la elaboración, 
como para la producción de normas que conlleven la mejor calidad técnica posible, así como un mayor acercamiento con la realidad social, de forma que sean consecuentemente obedecidas y aplicadas.

Para la realización de esto, el autor plantea su experiencia en materia del estudio lingüístico y lógico de enunciados jurídicos, mediante el desglose y examen, tanto en su origen (contexto de descubrimiento), como en su desarrollo (contexto de justificación), de cinco casos-modelo en las materias: agraria, bioética, constitucional, penal y municipal.

El modelo de análisis que formula en el caso agrario es particularmente atractivo. Primero, al haber sido empleado para el diseño del reglamento de la Ley Agraria con relación a la certificación de derechos (a través del delineamiento de los principales puntos de política normativa, a saber, qué se debe regular y qué no); segundo, porque hoy es imprescindible para crear y diseñar reformas en esta área.

Respecto de los enunciados penales que son estudiados, cabe destacar que tienen origen en diversos litigios de los que formó parte el especialista, resultando interesante el estudio al presentar ejemplos que no se deben seguir, pues destaca el efecto nocivo que provoca el abrumador e incontrolado empleo de conjunciones y disyunciones, así como el uso excesivo de términos imprecisos. Lo anterior incitó a Gutiérrez Parada, en cuanto al delito de fraude, a descomponer el enunciado del Código Penal respectivo para probar que la conducta de la inculpada que defendía no se subsumía al tipo penal, es decir, a la descripción de la conducta descrita.

En lo tocante al caso municipal cabe destacar lo que el maestro denomina "técnica de epígrafes", funcional para adquirir una mejor idea de los criterios para llevar a cabo la sistematización y ordenación de una ley.

La metodología es distinta según el caso de que se trate, así por ejemplo, el modelo agrario es analizado mediante nueve pasos, de los que cabe resaltar el estudio lingüístico y lógico (a través de un examen lexicográfico, sintáctico y semántico). También sobresale la inventiva para identificar los universos de acciones hipotéticamente posibles y de los sujetos agrarios.

Por su parte, las cuestiones penales son acreedoras de un método de examen propio, del que resaltamos el estudio de la significación de los conjuntos de palabras interdependientes y de los signos gramaticales, de la ambigüedad y vaguedad de los enunciados, de las inferencias necesarias para el análisis lógicojurídico y lingüístico, de la correlación de elementos para determinar los subtipos penales y, finalmente, de una técnica para la fijación de la sanción.

Los modelos y ejercicios son útiles en tanto que habitúan a analizar los enunciados, con la finalidad de comprender su estructura e identificar las locuciones que desempeñan un papel clave. 
La obra resulta eficaz para adquirir habilidades y operar, muy en especial, la racionalidad lingüística, así como vincularla con las demás dimensiones racionales del legislador (jurídico-formal, pragmática, teleológica y ética). Aquí es fundamental el empleo de modelos y las reglas para su instrumentación.

Dentro de su apartado de consideraciones finales, se señala que las técnicas para la elaboración de enunciados jurídicos requieren ser ensayadas para lograr concretarse, por lo que el objeto inmediato de esta obra consiste en ello, lo que se alcanza exitosamente a través de la presentación de las técnicas como modelos, así como de la exposición detallada de sus pasos.

Trabajo que nos recuerda la importancia del conocimiento interdisciplinario, debido a que para la producción de enunciados normativos, no basta la preparación jurídica, sino que es menester contar con aptitudes lingüísticas (ortografía, gramática, sintaxis, semántica) y lógicas, además de las relacionadas con la materia objeto de regulación, sin menoscabo de las cuestiones de orden social, político y económico.

El estudio y revisión de la obra que se reseña son imprescindibles para avanzar en los conocimientos sobre los diseños normativos y propiciar la mejora de la calidad de las leyes, por lo que se sugiere ampliamente su lectura. 